\title{
$\mathrm{D})$ 解 \\ Volume 4 - Spring 2008 djim.management.dal.ca
}

\section{Digital Audio Collections}

\section{Jason Tenter}

\begin{abstract}
This paper is about the possibility of libraries creating digital music or audio collections based on the current state of the digital music industry, and in comparison with the difficulties librarians have found in adding e-books to collections. In comparing the e-book and digital music markets, factors such as digital rights management (DRM) and the differences in both markets' relationships with customers are examined. This juxtaposition suggests that where e-books have been difficult to include in library collections because publishers want to maintain control over their content, music publishers have had to resign some of the control over their products because of file-sharing, and so may work with libraries to develop these collections in a more constructive way than e-book venders. At the end of the paper, some models are suggested for developing these collections.
\end{abstract}

About the Author: Jason Tenter has worked with digital media for several years, most notably with professor and multimedia artist Don Sinclair within the faculty of Fine Arts Cultural Studies at York University, in which he attained his bachelor's degree in 2004 . He is currently in the Masters of Library and Information Studies at Dalhousie University, and this paper was originally submitted as an essay in the course INFO 5500: Information and Society. Jason is an avid, award-winning writer, and an artist working with a variety of disciplines. 


\section{Introduction}

Music is an important part of library collections, and so it is important for information professionals to consider ways that we can offer diverse and culturally relevant material within the context of changing technology and access to information. Digital Libraries have been a common theme in writings and thinking about libraries for several years now. As journal collections and catalogues have moved online, the role of the library has evolved to be relevant to the connected environment. However the information profession is still in a state of flux, and there is an amount of uncertainty about where these changes will lead. E-books have been a part of this discussion for several years as many people hailed their arrival as a sign that print books would soon be obsolete, but so far they have only caught on with a core audience of dedicated users. Libraries have attempted to incorporate them into their collections, and although some have found success, there have been problems with this implementation, often for the same reasons that e-books have not become popular outside of libraries. Despite these problems, progress has been made towards lending e-books.

Some of the complications that have arisen in attempts to build collections of e-books stems from the publishing industry watching how the music industry has been affected by digital formats, and the ease with which these are shared over the internet. Publishers have watched as music sales have plummeted (Craig, 2003) and this has been correlated with music piracy using programs like Kazaa, and Napster, which was the original focal point of music sharing controversy around the beginning of the 21 st century. Although the music industry has tried to fight back, using digital rights management (DRM) as well as other means, these attempts have not stopped illegal file sharing. Recently, some of the leaders of major record companies have admitted that there is nothing they can do but evolve to the current market conditions. Experiments in selling music online have been going on for years, though, and have had some amount of success.

With these developments, the music industry has become increasingly contained on the internet, and this means librarians need to start thinking about developing digital audio collections. In this paper I intend to show why this might be the right time to develop this type of resource, and to share a few models previously developed within the music industry that could provide a good basis in making a collection such as this. To show the factors that might make a digital audio collection feasible for a library, I will first look at the incorporation of ebooks into libraries, and what has prevented them from becoming a prominent part of library collections. Digital audio files and e-books share many similarities, such as being digital formats whose content is easily copied and shared if not for protective DRM software, but these industries have developed dissimilar views regarding content sharing. Comparing these two industries should illustrate that the music industry may be more receptive a partner than the e-book industry has been, and allow libraries to develop a means of digitally sharing their 
releases that makes use of the potential sharing benefits the digital format allows (such as remote access, and no limits on the amount of users borrowing materials). I am choosing to use the term digital audio collections to describe this resource because although much of my discussion is focused on the music industry, this industry also releases non-musical material such as spoken-word albums. Digital audio collections can also include audio books, but these are not generally released by the music industry, and so are not subject to the same factors that may make that industry's releases viable for inclusion in this type of resource. Their inclusion here would only muddle this discussion. Finally, I will refer to the music industry by that name, despite non-musical releases, because this is what the industry is popularly called and since the majority of its releases are musical in nature.

\section{E-Books in Libraries}

For several years now, the e-book market has been struggling to take off, only existing as a market for a core group of followers. Recently there have been strong developments in the industry: there have been increases in sales, $\$ 8.1$ million in the $2^{\text {nd }}$ quarter of 2007 , up from $\$ 4$ million the previous year (Wayner, 2007), and new developments in technology like the Sony Reader which does not have daylight glare (which makes it difficult to see the screen in certain types of lighting. Wayner, 2007). Also, the International Digital Publishing Forum (IDPF) recently developed an e-book authoring standard (Rhey, 2007), the Open eBook Publication Structure Container Format or OCF. The latter development has been important because up until this point e-books were published using different file types, which meant that a customer could buy a copy of Truman Capotes' In Cold Blood and could only read the book using a specific reading program, which may not be compatible with their e-book reader. In developing an authoring standard the intent was to create a standard that all e-books would adhere to, and so facilitate the industry gaining a larger audience (Baker, 2007).

Still, these developments do not do much to counter long-standing problems within the industry. E-book readers are still expensive (Rhey, 2007), and although an e-book document standard has been developed, criticisms have been leveled against the IDPF's new standard because it continues to implement DRM software that some feel unfairly restrict the access to the content within e-books (Mitchell, 2007). DRM software is software embedded in products that can be copied, such as CDs, which restricts usage that might enable copying (Halderman \& Felten, 2006). It has the prescribed goal of protecting digital content rights, and DRM has been implemented by publishers in the e-book industry to try to protect books from being shared online in the same way that music has been. For many e-book customers, the restrictions used are found to be overbearing, such as barring owners from loading book titles onto a different device if they buy a new reader, or print text from a book they own (Mitchell, 2007; Craig, 2003). In addition, the development of the OCF does not guarantee that all ebook reading programs will adopt this standard, and so long-standing formatting problems may 
still exist. All of these factors have been noted as keeping e-books from gaining a strong, populous audience, and DRM in particular is viewed as keeping e-books so secure that neither the public nor libraries can use the content (Craig, 2003).

E-books could be a great resource to a library, particularly for patrons with accessibility problems such as mobility impairments (Berube, 2005), and because they can be searched easily, they have gained a foothold in reference sections of academic libraries; vendors have even relaxed DRM restrictions on printing pages with these books to make researching more convenient for students (Safley, 2006). Still, restrictions on e-books limit the potential benefits of the technology making it often a wiser decision for a library to buy print books. In his efforts to introduce e-books into the Essex Public Libraries, James Dearnley (2004) outlined several problems. In developing this project, he explored single e-book purchases and subscriptions to e-book vendors, ultimately finding that purchasing e-book packages was much more practical because of the number of books that could be accessed and less severe DRM restrictions (2004). These suppliers have become a popular means of incorporating e-book into the library, especially when testing interest in a community (Craig, 2003). Still, as Dearnley learned, the content these vendors offer is almost as restrictive as single titles. Between NetLibrary, ebrary and OverDrive, only OverDrive did not allow more than one patron to access a book at the same time, however it is the only one of the three that allows a borrower to put an e-book on a portable device (Dearnley et al., 2004; NetLibrary, 2007). This is strange, as the policy snubs people who use e-readers, which is a large part of the core e-book audience.

There were other problems that Dearnley and others have noted with introducing e-books into libraries. Attempts to incorporate e-book readers have been unsuccessful, partly because of the expense of the device but also because of the difficulty in maintaining electronic devices and a lack of interest. In fact many programs, after implementation, do not get developed any further (Dearnley et al., 2004; Craig, 2003). There are also difficulties stemming from e-book publishers' use of different formats for their books, requiring different readers, which as mentioned earlier may not change with the development of the IDPF's new authoring standard. This has limited what content can be read using each reading device, or on a library's or patron's computer (Dearnley et al., 2004); in general it makes managing collections difficult. Strangely, e-book vendors do not see it to be a problem, saying that to them it is not a major concern (Grogg \& Ashmore, 2005). For these and a variety of other reasons, some librarians have simply decided to forego collecting e-books (Craig, 2003). 


\section{Digital Rights Management}

Digital rights management is a problem only from the vendor's point of view. The problem is that they don't believe in fair use at all. They're trying to control rights that people already have pretty well established, and they're trying to do it under the label of 'digital rights management.' (Craig, 2003, pp. 1111-1112)

The difficulties of collecting e-books experienced by libraries have suggested to some librarians that e-book publishers (and publishers in general) do not like libraries very much (Craig, 2003; Berube, 2005). One librarian, while looking at her own process of building an ebook library, felt that publishers look at each lending as one less sale, and that overall these publishers saw libraries as a 'drain on profits' (Berube, 2005, p. 16). In a study done by Claire Elizabeth Craig (2003) of the incorporation of e-books into law libraries and public libraries in America, several librarians were interviewed and a general consensus emerged that although librarians want to incorporate e-books into their libraries, and had begun experimenting with vendors like NetLibrary, substantial use was prevented by publishers' and vendors' use of DRM to overzealously protect their digital rights. The message that came from this study was that there had to be compromise on the part of e-book publishers with regard to the level of restriction on their titles before they would have a significant place within libraries.

In her study, Craig did note that copyright holders were sensitive to the developments in the music industry thanks to Napster and other file-sharing programs (2003). It is easy to see how the e-book publishing industry would be afraid of going down the same rabbit hole of piracy, and therefore why it is important for them to have protective measures in place around their content. However, some of the steps taken by the industry to protect its profitability can also be seen as a way of sneakily trying to increase profitability. Michael Hart, the founder of Project Gutenberg, was interviewed along with representatives from several e-book vendors, and in the interview he said that many in the industry want to charge as much as possible for ebooks, despite the differences in costs associated with selling and distribution. The Senior Vice President of Sales and Marketing for ebrary said that companies should charge the same for an e-book as for a print book, and let consumers choose which format they want (Grogg \& Ashmore, 2005). When you look at the differences in costs between distributing, storing and selling both formats of a book, it does seem unrealistic to charge the same price for an e-book as for a print book. Although it is reasonable for publishers to want to defend against e-book piracy using DRM, Hart's observation suggests that DRM is also used to squeeze more profits from libraries and consumers while violating their fair use and fair dealing rights. For libraries this profit seeking restricts their ability to fulfill their role (Craig, 2003), and it does not make sense for vendors as it alienates this market even while they say libraries are valuable customers of their service (Grogg \& Ashmore, 2005). 
This is not to say that profit should not be a concern for the publishing industry, but there needs to be a balance that respects a library's right to share content, a right which is seen as essential for libraries in the US, the UK and Canada (under the fair use policy for the first, and fair dealing for the latter two. (Berube, 2005; Davis, 2004). Part of the problem currently seems to be that governments do not know how to deal with the ease of copyright violation allowed by the internet any more than sellers of intellectual property, and how this should affect copyright policy for multimedia works in educational environments (Davis, 2004; Carroll, 2007). One thing the e-book publishing industry should learn, which the music industry is finally realizing, is that DRM can alienate them from their audience. Music labels have been trying to combat illegal music downloading for years using DRM, the most infamous instance of this being protection used on Sony-BMG CDs that installed a hidden device onto customers' computers allowing the company to monitor use, but also allowing enterprising hackers to easily obtain access to these same computers (Halderman \& Felten, 2006). Moves such as these, and strong-arm tactics like suing music downloaders, have not stopped music sharing online but instead made customers feel uncomfortable with music labels. It is only recently that the music industry has understood that it needs to approach consumers in a more amicable way if they want to remain a profitable industry, and evidence of this is discussed below. Friendlier types of DRM have also been developed in recent years to try to draw consumers toward buying digital music. There are several approaches taken in these management systems (which will be looked at later on in this paper) that inhibit sharing with many people but not use on portable devices or in other ways that e-books have limited their customers.

\section{The Music Industry}

Edger Bronfman, CEO of Warner Music, recently stated:

We used to fool ourselves. We used to think our content was perfect just exactly as it was. We expected our business would remain blissfully unaffected even as the world of interactivity, constant connection and file sharing was exploding. And of course we were wrong. How were we wrong? By standing still or moving at a glacial pace, we inadvertently went to war with consumers by denying them what they wanted and could otherwise find and as a result of course, consumers won. (Sullivan, 2007)

This statement came weeks after the decision by one of the world's most popular contemporary rock bands, Radiohead, to release their album In Rainbows online for an amount of the buyer's choosing. There was precedence towards Bronfman's statement even at the beginning of 2007, when at the music conference Midem, it was announced that one of the four major record labels would begin selling digital music files without embedded DRM software in the months that followed, and there was talk about other labels increasingly moving into this territory (Shannon, 2007). Although this has not happened yet, the release of $I n$ 
Rainbows seemed to get the ball rolling. A few days after Radiohead announced the release of their new album, and its method of distribution, Guy Hands, the new owner of EMI music, also announced that EMl's focus as a company would be reassessed, with a focus towards existing in the new digital environment, and instead of giving musicians large advances to produce an album and for touring, a system which indentures musicians to labels, an alternative might be to subsidize recording an album for a share of the profits (Essen, 2007).

One of Hands' fears is that more musicians will turn away from labels and release music to fans directly (Essen, 2007), a tactic many musicians have begun to take. Trent Reznor of Nine Inch Nails has spoken out during concerts encouraging his audience to steal his music (Ryandashsdotorg, 2007), and he encouraged poet and hip-hop artist Saul Williams to release his most recent album online ("Trent Reznor," 2007). It has been a trend for several years for albums to be leaked to consumers several months before release, often frustrating record labels, and although it is hard to know who is behind these acts, even if not directly, the musicians themselves might in some cases be encouraging this (for an in-depth discussion of musicians who encourage sharing music online, see McLeod, 2005). Peer-to-peer music sharing has in some ways created a better place for musicians themselves, as independent artists can promote their music easily by trading music, and generate a fan base who will buy merchandise and pay to see them play live (McLeod, 2005). For many artists this is a terrific way to release music without having to compromise their artistic vision to get a contract, and several music vendors exist who sell both CD and MP3 versions of albums.

So it is evident that, just as fans are happy to consume music in the form of digital files shared online, musicians also find freedom in releasing music through the internet, and music labels have begun changing their models to continue being relevant in the market following this change. This has not meant that companies have been ignoring the internet, though, as for years they have been working on models for selling music online. The most popular venture to come from this initiative has been Apple's iTunes Store, which has had progressively increasing sales. Its initial sales in March 2004 were 50 million downloads, and this rose to 250 million by January of 2005, and 600 million by November 2005 (George \& Chandak, 2006). There is a problem with this industry in that online sales are not replacing money being lost from CD sales (Shannon, 2007). Even Apple reports that it loses money from the iTunes store, but it makes up for this in its sale of iPods (George \& Chandak, 2006). Still this is a large amount of sales to people who could easily get the same file for free. Also, different reports have shown that individuals who download music are increasingly likely to buy music (Dubosson-Torbay, Pigneur \& Usunier, 2004; McLeod, 2005), and although this does not account for money that is lost by major record labels this might be because it is going to independent artists and music labels. Labels seem to be realizing that the old system of music distribution cannot be revived, and neither can previous levels of profits, but this has motivated 
them to be open to the digital market in new ways. As the Music World chain closes its doors and moves online (Kubacki, 2007), it is just another sign pointing towards the music industry becoming an entirely digital entity.

\section{Why Digital Audio Collections Could Work within Public Libraries}

Although there have been problems in developing an e-book presence in digital libraries, many of the same factors are not as much of a problem for music. Many e-book vendors and publishers restrict how many reading devices can contain a copy of a book, and other access to the text such as copying and printing, but the music industry has taken a more lenient approach to try to draw back customers. The DRM on songs that are purchased online generally is more relaxed. For instance Ministry of Sound, a British dance music label and online store, allows a subscriber to download a music track that will expire at the end of month, and then if the listener wants, they can buy the song. Most digital music vendors allow use on portable devices, including Sony, iTunes, and Napster, although only the ones enabled with that vendor's particular DRM (George \& Chandak, 2006). As previously mentioned, some ebook vendors used by libraries don't allow e-books to be used on portable devices, but these music vendors allow purchased songs to be used on at least three computers each and unlimited portable devices (Dearnley et al., 2004; NetLibrary, 2007; George \& Chandak, 2006). Although both instances are from different circumstances, one referring to use in a library and the other sale to the public, there is still a stark difference between the restrictiveness of music vendors and that of e-book vendors. There are other limitations on music files sold by these vendors, such as restrictions to the number of times a music file can be used on a certain playlist and burnt to a CD, but these still allow a variety of use where many e-books don't even allow a user to cut \& paste a section of text (George \& Chandak, 2006; Craig, 2003). Although the DRM used by the music vendors is restrictive, they still strike a balance between the rights of copyright holders and fairness to owners. This suggests that it might not be difficult to establish a system, both with DRM and with distributors in the system, for sharing digital sound files or digital music through a library. For instance, an album a library shares could be downloaded and listened to for a period of time, after which the file 'locks' and cannot be used anymore. The concessions that the music industry has made in managing content should help the industry to be compatible to libraries' needs.

One dilemma that does come up when looking at the music industry's use of DRM is a problem of music file formats. Similar to the problem the e-book industry has of having too many file-types that can only be used with specific reading software, music publishers wants to use their own file formats to maintain a degree of control over the market. iTunes is again the best instance of this, as they only produce files in a specific format, and limit which types of sound files can be used on iPods, thus ensuring a dedicated audience for their products. And 
although attempts have been made by other companies to convince Apple to create interoperability with other models, they have not budged in their stance (George \& Chandak, 2006). The differences in sound file format will factor hugely into how libraries incorporate the technology. If the system of sharing the collection is through downloading files then some patrons might be limited in usage. Certainly this would be problematic with regard to portability, as providing content in a Windows Media file format would restrict use by iPod users. Operating systems might also factor into formatting issues, such as including content that can be experienced through Windows, the Mac OS, and Linux.

A reasonable alternative to formatting that might satisfy both copyright holders and the goals of the library would be through audio streams. This satisfies both the goal of lending, while enabling the availability that digital media inherently allows, but it does not give the patron the same option to bypass DRM as downloaded files might. There are drawbacks to this model, though, that are also reflective of offering downloads from the library's site. For one, not every patron is going to have the bandwidth to stream audio content or to download it quickly, and if there are many users streaming audio at the same time it will be a strain on the server the audio files are on; libraries would also need to take into account the bandwidth of their own internet connection so that it can accommodate a large number of users. This also brings up the dilemma of the digital divide, which a digital audio collection would increase. Libraries could provide computers designed as listening stations, but it is likely they would need several computers to be accommodating, and so expensive to implement. Finally, music companies might have a problem with music being so easily accessible. This library model works against traditional music industry models that seem to share the same sentiments as e-book publishers with regard to ownership and fair dealing. However, as previously noted, the music industry has recently changed its prerogative somewhat with regard to music sharing, and is now trying to be open to new models. This is perhaps the best time to approach developing a digital audio collection, and depending on how a library chooses to implement this it could be beneficial to the public, and also music labels who could profit from the sale or lease of their content.

\section{Individual Models}

Dubosson-Torbay, Pigneur and Usunier (2004), in a paper presented at the WEDELMUSIC conference, outlined a variety of business models for selling music online. Since then the industry has changed as certain models have proven more successful than others in selling to a mass audience. A few of these models might make sense for libraries to use in creating a digital audio collection.

The model that is most easy to imagine libraries committing to is the subscription model. This type of service functions in the same way that e-book vendors like ebrary do, or as journal 
databases do, offering a subscriber a certain number of downloads within a month, and streaming audio. The first subscription-style music services were started by labels as a way to create a legitimate alternative to illegal downloading (Dubosson-Torbay, Pigneur \& Usunier, 2004). EMI created MusicNet (with AOL, Real Networks and Bertelsmann) and Sony and Vivendi Universal started Pressplay (2004), but neither of these sites has done well for a variety of reasons (they were even voted amongst the top- 25 worst tech products of all time. Tynan, 2006). Part of the problem was that these sites offered a limited number of songs since they only offered albums from the catalogues of the labels behind them (Dubosson-Torbay et al., 2004). Because of the success of iTunes and the 'a la carte' model it represents (a system where customers can buy individual music tracks and albums. Dubosson-Torbay et al., 2004), most subscription sites existing presently are a combination of the subscription and a la carte models, however as libraries do begin to develop digital music collections it is likely that labels or other groups might develop subscription-only sites that are geared towards libraries' needs, and which will offer a good selection of music with reasonable rates.

The combined subscription and a la carte model is also a reasonable option for libraries, although there are some factors that might make it less than desirable, the primary one being that it is a model for selling music. As this model became popular, several other services started to develop models combining subscription service with this form, including Napster, MusicNet, and Real Network's Rhapsody. With this bundle service, a subscriber can listen to music, in some cases downloading expiring tracks and in others simply streaming audio, and then have the option to purchase them. This might not be a model that some librarians would want to incorporate, especially as it turns the library into a store in some respects, however it might make for a more affordable service. Also, there is an example of this service that libraries already subscribe to: The Classical Music Library (Alexander Street, 2005). In the Classical Music Library database (the CML), a library patron can stream music and create a "playlist" of music tracks, and save these in profiles that they can create. The database also allows a patron to purchase music through the database, although this is not an intrusive element to the experience of the site (2005). So, the CML acts as an example of a database that allows libraries to provide access to music through a subscription service, and the service itself would also sell music to the user, albeit in an unobtrusive manner. This model may not fit with a view some librarians have of the role of the library, but for others it might be a practical approach to allowing their patrons to access information. Also, as with subscription services there is still a problem with content being limited to the labels that make agreements to participate with the service, and independent artists may be left out of these services.

The third option would be somewhat more practical for developing a wide range of material. With the above two models a library might not get the best range of content; even if they did subscribe to a few services, including one that offered music from independent labels and 
artists, they might miss out on other valuable content. Alternatively, they might choose to develop their own digital audio library, purchasing and using their own server space to contain the files. This would be a big project, but there is no reason why a district could not develop this and upload the material they already have in their collections. This would create a permanent music collection for the libraries, instead of simply leasing one, and their budget would be used towards adding to this, as well as to upkeep. It would also allow librarians to choose what material should be shared, not simply what is available through commercial sites. As with the previous two models, however, there are drawbacks to this one as well. Aside from the financial commitment and training involved in a library developing its own digital sound library, there is also the potential that labels might take issue with libraries sharing material through downloads, even if the means of doing this does not facilitate piracy. In 2001, MP3.com was sued for allowing members to stream music files from albums that they had proven they owned. The service was designed to allow users to access their collections from different computers, and when sued they argued that it was their right to provide this service because of fair use. However the judge disagreed and MP3.com ended up paying hefty settlements to the group of labels that filed suit (Dubosson-Torbay et al., 2004, p. 277).

Unlike the previous two collection models, which would not raise copyright concerns since labels are leasing their property and consistently profiting, this model is likely to face contention, despite a library having already paid for the music in another format, and being able to lend that item. Were libraries to develop their own digital audio library, they might have to fight a similar battle as MP3.com, even if the files are lent through streaming audio; however, this might also not be the case as labels are increasingly willing to make compromises since it would be just as easy for a patron to find an illegal copy of an album as to stream it from a library website. It could be an essay unto itself to argue that libraries should be able to share content in the way this model suggests, based on previous fair dealing and fair use legislation in North America and the UK which seeks to protect educational sharing of material (Berube, 2005). The future rights libraries have to share their own expansive digital audio collections will largely depend on how each country's policy is updated, but also how libraries and other educational bodies work to create collections now as the environment changes.

These previous models are the most likely options for a library, as suggested by DubossonTorbay, Pigneur and Usunierpaper, although there are a few other models that might be considered as well. There is the distribution model, where a customer streams a whole catalogue of music, then pays for the tracks they want. A library might be able to work out some type of deal with a distributor (Dubosson-Torbay et al., 2004), buying a whole catalogue from them, or leasing it, and then streaming it to their clients. Alternatively, a company might ask a library to use advertising to subsidize the service, or embed programs that would record 
demographics information from users (Dubosson-Torbay et al., 2004). These last two options seem unlikely for librarians to find acceptable, though. There are a few overall problems with many of these models, as well, in that they require vendors to initiate them, and these vendors might decide to set the same restrictions that e-book vendors do, such as only allowing one patron to borrow an album at a time. This would not be practical, though, considering the ease with which a client can find music elsewhere. Also, as noted previously, because labels are accepting the changes in the industry the tendency has been to move away from DRM restrictions, not towards them.

\section{Conclusion}

As the music industry increasingly makes its home on the internet now that listeners choose to consume music online, libraries are going to have to consider how to reconcile this change in their collection practices. So far the development of e-book collections in libraries has been less than ideal, as publishers maintain overly secure DRM restrictions, but creating a digital audio collection should be an easier prospect. For one thing, the music industry is realizing after several years of trying to fight illegal downloading through lawsuits and poorly-designed DRM that it has been fighting a losing battle, and now they are looking at how to exist with the changes that technology has brought. For them this might be an evolution, and they might be able to treat libraries' fair dealing and fair use rights with respect as long as a model that respects copyright is implemented. With this in mind, it might only take a few experiments in development to make a digital audio collection work, one that strikes a fair compromise between copyright holders and librarians.

There are several questions and discussions that arise when thinking about creating this type of resource within a library that I have chosen not to explore, but would like to call attention to. For instance, the discussion of how the concept of ownership and collection changes if libraries increasingly use outside firms to provide digital content. Increasing reliance on leased content from vendors seems like a dangerous path, as it removes a certain amount of power a library should have over its collection, whether through deciding on content or having a permanent collection that will not change or be removed as readily as a leased one can. If this trend continues it could undermine a library's autonomy and ability to act for the well-being of the public. Additionally, the idea of creating a digital audio collection also presents the opportunity to create an archive of music that is obscure but culturally relevant. For a variety of musical genres including R\&B and Punk there are a number of albums that had limited release and are hard to find but which could be digitally transferred and made available to musicologists and audiophiles the world over, as well as for future generations. It would be valuable to create this type of resource, and developing digital audio file collections in libraries would be a great step in this direction. 


\section{References}

Baker, Pam (June 29, 2007). The next chapter for e-books. From E-Commerce Times, retrieved February 16, 2008, from http://www.ecommercetimes.com/story/OlzzGQnOQrPywV/The-NextChapter-for-eBooks.xhtml?welcome $=1203188350$

Berube, L. (2005). E-books in public libraries: a terminal or termination technology? Interlending \& Document Supply. 33(1). 14-18.

Carroll, Michael W. (2007). Fixing fair use. North Carolina Law Review. 85, $1087-$ 1154.

Craig, C. E. (2003). Lending institutions: The impact of the e-book on the American library system. University of Illinois Law Review. (4), 1087-1114.

Davis, J. (2004). Copyright reform and digital libraries in Canada. Retrieved November 11, 2007, from http://textsfornothing.com/resume/copyright_reform_dig_libs.pdf

Dearnley, J., Morris, A., McKnight, C., Berube, L., Palmer, M., \& Joanne, J. (2004). Electronic books in public libraries: A feasibility study for developing usage models for web-based and hardware-based electronic books. New Review of Information Networking, 10(2), 209-246.

Dubosson-Torbay, M., Pigneur, Y., \& Usunier, J.-C. (September 13, 2004). Business models for music distribution after the P2P revolution. Proceedings from WEDELMUSIC 2004: The Fourth International Conference on Web Delivering of Music. 172-179. Lausanne Univ., Switzerland.

Essen, Y. (October 9, 2007). EMI warning on internet music. From Telegraph, retrieved November 7, 2007, from http://www.telegraph.co.uk

George, C., \& Chandak, N. (November 1, 2006). Issues and challenges in securing interoperability of DRM systems in the digital music market. International Review of Law, Computers \& Technology. 20(3), 271-285. 
Halderman, J. A., \& Felten, E. W. (June $21^{\text {st }}, 2006$ ). Lessons from the Sony CD DRM episode. From 15th USENIX Security Symposium (p. 77-92 of the proceedings), retrieved November 15, 2007, from

http://www.usenix.org/events/sec06/tech/full_papers/halderman/halderman - html/

Kubacki, M. (November 13, 2007). Last Canadian music chain, Music World, closes. From The Vancouver Sun, retrieved November 20, 2007, from http://www.canada.com/vancouversun/news/business/story.html?id=8d17e 6bd-ec94-4870-81c7-8a5e959115c9

McLeod, K. (October 1, 2006). MP3s are killing home taping: The rise of internet distribution and its challenge to the major label music monopoly. Popular Music and Society. 28(4), 521-531.

Mitchell, S. (October 31, 2007). Analysis: eBooks making same mistakes as music industry. FromPC Pro, retrieved November 11, 2007, from http://www.pcpro.co.uk/news/134241/analysis-ebooks-making-samemistakes-as-music-industry.html

NetLibrary. (2007). Retrieved November 20, 2007, from http://company.netlibrary.com/aboutus.aspx

Alexander Street Press | Classical Music Library. (2005). Retrieved January 18, 2008, from http://alexanderstreet.com/products/clmu.htm

Rhey, E. (May 31, 2007). Book Expo America 2007: The state of ebooks. From Gearlog. Retrieved November 11, 2007, from http://www.gearlog.com/2007/05/book_expo_america_2007_the_sta.php

Ryandashsdotorg (Septermber 16, 2007). "Steal it!" - Trent Reznor is honest and logical. Retrieved November 6, 2007, from http://www.youtube.com/watch?v=TJ5iHaV0dP4

Safley, E. (November 21, 2006). Demand for e-books in an academic library. Journal of Library Administration. 45(3-4), 445-457. 
Shannon, V. (January 21, 2007). Record labels rethink digital rights management at Midem. From The International Herald Tribune, retrieved November 15, 2007, from http://www.iht.com/articles/2007/01/21/yourmoney/music.php/

Sullivan, M. (November 15, 2007). Warner music CEO: We went to war with consumers. From PC World, retrieved November 15, 2007, from http://blogs.pcworld.com/staffblog/archives/005933.html

"Trent Reznor (Nine Inch Nails) produced album by Saul Williams yours for zero dollar" (November 1, 2007). From Side-Line, retrieved November 20, 2007, from http://www.side-line.com/news_comments.php?id=26846_0_2_0_C

Tynan, D. (May 26, 2007). The Worst tech products of all time. From PC World (Numbers 6 to 10), retrieved November 15, 2007, from http://www.pcworld.com/article/id,125772 page,3c,techindustrytrends/article.html

Wayner, P. (August 9, 2007). An entire bookshelf, in your hands. From The New York Times, retrieved November 11, 2007, from http://www.nytimes.com 